\title{
Call for human subjects monitoring body
}

[SAN FRANCISCO] The US National Bioethics Advisory Committee is to examine the possibility of setting up a single, independent body to oversee the protection of human subjects in all federally funded research.

At a meeting of the committee's human subjects subcommittee in Bethesda, Maryland, last week, Alexander Capron, co-director of the Pacific Center for Health Policy and Ethics at the University of Southern California Law Center, and a former executive director of a presidential ethics committee under President Jimmy Carter, proposed commissioning papers to examine the matter.

Capron suggested the Office of Government Ethics as a potential model for an agency to oversee research. This became an independent body in 1989, its role being to maintain high ethical standards within executive branch agencies and departments.

The independent organization being considered by the bioethics committee would monitor problems in research on human subjects, and would be able to demand compliance by government bodies.

Capron argues that there has always been an inherent conflict within agencies that monitor their own research. As the rules that govern informed consent and other protective measures become more burdensome, officials at the National Institutes of Health have had to increase their emphasis on promoting the research. If research within an agency is overseen by that agency itself, he says, "I'm sceptical it will ever be possible to have as vigorous and thorough attention to protection of the human side as to moving research forward".

An independent agency or department could protect human subjects without such pressure, Capron says. The committee has commissioned one paper to examine the benefits of such an approach and another to define the drawbacks. For instance, there is a risk that Congress would reduce an independent entity's funding or narrow its authority, or that the agency could become dominated by a particular area of research.

The need to get on with trials could also lose priority. Project Informed, an AIDS research project in San Francisco, has voiced concern that an independent body could get bogged down in bureaucracy.

At the recommendation of David Cox, professor of genetics and pediatrics at Stanford University and a member of the subcommittee, a third paper will consider whether private research should be in the new office's purview. Cox has argued that the division between private and public research has become artificial.

Cox warns that clear protective measures for human subjects need to be in place for the public to feel comfortable about taking part in research. In one study of genetic testing, for example, 30 per cent of patients refused to participate because they were worried about privacy.

Capron notes that a bill introduced by Senator John Glenn (Democrat, Ohio) would require private research laboratories to register with the Health and Human Ser-

vices Department. Glenn told Congress he was concerned about four major gaps in the current system to protect human subjects.

The four gaps were: that not all agencies, including the Department of Labor and the Nuclear Regulatory Commission, had adopted the common rule for human

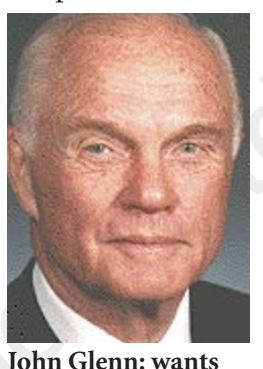

John Glenn: wants labs to register. subjects research; that federally funded institutions needed to apply the policy only to funded research; that private institutions did not need to comply; and that only Health and Human Services had special protective measures for vulnerable categories of people such as children and prisoners.

Glenn pointed to examples reported in the Cleveland Plain Dealer and elsewhere in the media where people did not know they were taking part in research or did not know about potential side-effects.

According to Capron, private institutions may have their own internal office for protection of human subjects, but overall monitoring might be accomplished more effectively from the outside.

Gary Ellis, director of the Office of Protection from Research Risks at the National Institutes of Health, wants to extend legal protection to those taking part in private research projects that are not participating in the current voluntary system. Sally Lehrman

\section{Collins' student sanctioned over 'most severe' case of fraud}

[SAN DIEGO] A former star student of the director of the Center for Human Genome Research at the US National Institutes of Health (NIH) has been barred from federally funded research for four years and denied his doctorate after one of the United States' biggest cases of scientific misconduct.

Amitov Hajra, a doctoral candidate who worked with the NIH genome chief Francis S. Collins in both Ann Arbor, Michigan, and Bethesda, Maryland, agreed to the penalty after an investigation by the NIH's Office of Research Integrity (ORI). Hajra was also studying for a medical degree at the University of Michigan.

Probes by Michigan and ORI established that Hajra had fabricated 75 to 90 per cent of the data in his doctoral thesis on a possible genetic cause of a leukaemia.

He then used fabricated data to produce five articles published in 1995 and 1996, included falsified data in two review articles, and entered a bogus nucleotide sequence in GenBank, a computer database. All the fake research has been retracted or corrected. Neither Collins nor other co-authors were found to have had any involvement in the misconduct (see Nature 384, 6; 1996).

In their report delivered in March, Michigan officials referred to the "severe impact" the case had on "the public's confidence in science". They wrote: "On a scale of 1 to 10, with 10 being the most severe, the committee concludes that the academic misconduct here rates 10."

Hajra, who is now in Wisconsin, could not be reached for comment.

Michigan officials found the fabrications began when Hajra "suddenly blurted out" fake experimental results at a laboratory meeting. Afterwards, the report says, "he states he was so ashamed and confused by his behavior that he was unable to consider confessing to his wrongdoing."

Collins, who had brought Hajra with him when he was recruited in 1993 to the $\mathrm{NIH}$, says: "He was very motivated, determined and clever. I still don't know how he produced some of the primary data he brought to lab meetings. I find myself now being more vigilant, viewing data with more scepticism, which I'm not sure is a good thing."

Chris B. Pascal, acting director of ORI, commended Collins for the forthright way he handled the misconduct, which Collins first disclosed in a widely distributed letter after a reviewer found possible fabrication in a Hajra paper submitted to the journal Oncogene. The paper was withdrawn.

"He [Collins] reacted as best he could, confronted the individual and got an admission," says Pascal. "His reaction was more positive than we get from a lot of big shots, who engage in denial and in some cases cover-up."

Michigan will not grant Hajra his doctorate in human genetics. But Hajra continues to fight to secure his medical degree. A Michigan spokeswoman said the university had not decided whether to award Hajra this qualification. Rex Dalton 